\title{
Perception, knowledge, and attitudes towards molar incisor hypomineralization among Spanish dentists: a cross-sectional study
}

Clara Serna-Muñoz ${ }^{1}$, Yolanda Martínez-Beneyto ${ }^{2^{*}}$ (D, Amparo Pérez-Silva ${ }^{1}$, Andrea Poza-Pascual ${ }^{3}$, Francisco Javier Ibáñez-López ${ }^{4}$ and Antonio José Ortiz-Ruiz ${ }^{1}$

\begin{abstract}
Background: Molar incisor hypomineralization $(\mathrm{MIH})$ is a growing health problem, and its treatment is a challenge. The purpose of the present study was to evaluate and compare the perceptions, knowledge, and clinical experiences of MIH in general dental practitioners (GDPs) and paediatric dentists (PDs) in Spain.

Methods: All dentists belonging to the College of Dentists of the Region of Murcia, in the South-East of Spain, were invited to participate in a cross-sectional survey. They were asked to complete a two-part questionnaire including sociodemographic profiles and knowledge, experience, and perceptions of MIH. Data were analysed using Pearson's chi-square test, Fisher's exact test and Cramer's $\vee$ test.

Results: The overall response rate was 18.6\% (214/1147). Most respondents were aged 31-40 years (44.86\%), with more than 15 years of professional experience (39.72\%). They worked mainly in the private sector (84.58\%) and were licensed in dentistry (74.30\%): $95.45 \%$ of PDs had detected an increase in the incidence of MIH in recent years $(p<0.001)$. Only $23.80 \%$ of GDPs claimed to have made a training course on $\mathrm{MIH}$. With respect to the aetiology, chronic medical conditions $(p=0.029)$ and environmental pollutants $(p=0.008)$ were the only factors that showed significant betweengroup differences. Durability $(p=0.009)$ and remineralization potential $(p=0.018)$ were the factors where there was a between-group difference in the choice of the restoration material. In the case of post-eruptive fractures and opacities, the preferred material for both groups was resin-modified glass ionomer (RMGIC). However, in incisor lesions, composite was the material of choice for both groups, with significant differences $(p=0.032)$ in the use of glass ionomer. Most respondents expressed a need for continuing education on $\mathrm{MIH}$.

Conclusion: Spanish dentists perceived an increase in the incidence of $\mathrm{MIH}$. The material of choice was RMGIC for non-aesthetic sectors and composite for incisors. Dentists believe it is difficult or very difficult to manage $\mathrm{MIH}$, since the long-term success of restorations of MIH lesions is compromised because resin adhesion is not good. Both GDPs and PDs believe they need more training on the aetiology, diagnosis, and treatment of MIH.
\end{abstract}

Keywords: Molar incisor hypomineralization, Knowledge, Perception, General dental practitioners, Paediatric dentists

* Correspondence: yolandam@um.es

2Unit of Preventive and Community Dentistry, Department of Dermatology,

Stomatology, Radiology and Physical Medicine, Faculty of Medicine-Dentistry,

University of Murcia, Hospital Morales Meseguer, 2a planta, C/ Marqués de

los Vélez, s/n., 30007 Murcia, Spain

Full list of author information is available at the end of the article

(c) The Author(s). 2020 Open Access This article is licensed under a Creative Commons Attribution 4.0 International License, which permits use, sharing, adaptation, distribution and reproduction in any medium or format, as long as you give appropriate credit to the original author(s) and the source, provide a link to the Creative Commons licence, and indicate if changes were made. The images or other third party material in this article are included in the article's Creative Commons licence, unless indicated otherwise in a credit line to the material. If material is not included in the article's Creative Commons licence and your intended use is not permitted by statutory regulation or exceeds the permitted use, you will need to obtain permission directly from the copyright holder. To view a copy of this licence, visit http://creativecommons.org/licenses/by/4.0/ The Creative Commons Public Domain Dedication waiver (http://creativecommons.org/publicdomain/zero/1.0/) applies to the data made available in this article, unless otherwise stated in a credit line to the data. 


\section{Background}

The term molar incisor hypomineralization $(\mathrm{MIH})$ was described by Weerheijm, et al. in 2001 and adopted by the international dental community due to a consensus at the Congress of the European Academy of Paediatric Dentistry in Athens in 2003 [1]. MIH is defined as a qualitative enamel developmental defect of systemic origin that affects one or more first permanent molars with or without the involvement of permanent incisors [1]. When it appears in primary teething it is called hypomineralized second primary molar (HSPM), and predominantly affects the second molars and canines and is regarded as a predictive factor for $\mathrm{MIH}$ in the permanent teeth [2].

Historically, in the dental literature, a wide variety of terminology and definitions for enamel defects in hypomineralized molars, with or without post-eruptive enamel fractures have been used: enamel opacity not caused by fluoride, internal enamel hypoplasia, nonendemic enamel speckling, opaque stains, idiopathic enamel opacities, and enamel opacity. Some terms simply describe the pathology, while others bear the name of the causal agent [3]. Despite the many reports on its aetiology, the causal factors of MIH remain unclear [4].

Clinically, the form of presentation and the severity of $\mathrm{MIH}$-affected teeth may be asymmetrical in the same patient and vary from mild opacities to severe posteruptive breakdown that may affect from one to four first permanent molars [5]. MIH may be difficult to diagnose, and it may be confused with other conditions such as enamel hypoplasia, fluorosis and amelogenesis imperfecta. However, in enamel hypoplasia, the lesion consists of a local reduction of the thickness of the enamel, with regular, smooth and rounded borders while, in enamel fractures with $\mathrm{MIH}$, the borders are irregular and anfractuous; the enamel opacities observed in fluorosis are diffuse and symmetrical, in contrast to the well-demarcated lesions of the enamel in $\mathrm{MIH}$; lesions due to amelogenesis affect all the teeth, as this is a hereditary, genetic disorder, while lesions due to $\mathrm{MIH}$ are asymmetric and are located in the first permanent molars and incisors. In addition, the diagnosis may be complicated by secondary cavity lesions due to their rapid formation and progression in a highly-porous substrate [6].

The global recorded prevalence of MIH ranges from 2.4 to $40 \%$ and differs between countries $[7,8]$. There are a limited number of studies on the prevalence of $\mathrm{MIH}$ in Spain, where the prevalence varies from 7.94\% [9] to $11.1 \%$ [10], $17.8 \%$ [11] and $21.8 \%$ [12].

The high prevalence and incidence of $\mathrm{MIH}$, the poor quality of life of paediatric patients and the difficult clinical management, have led to numerous studies on the perception, diagnosis and management of MIH through surveys of dentists, both general dental practitioners
(GDPs) and paediatric dentists (PDs) [13-22]. In Spain, despite the high prevalence described in some areas, no studies have been conducted on how dentists act in the face of MIH. The objective of this study was to evaluate perceptions and knowledge about the diagnosis and management strategies of MIH of GDPs and PDs in the Region of Murcia, in the south east of Spain.

\section{Methods}

\section{Sample and procedures}

The study was approved by the Bioethics Committee of Murcia University (Reference Number: 2255/2019). Google Survey software was used to develop the survey that was subsequently emailed to all members of College of Dentists of Murcia $(n=1147)$ in March 2019. The email explained the study, stated that participation was anonymous and voluntary, and enclosed a link to accede to the survey without signing in to Google. The study researchers had no access to the personal data of participants. Participants were asked to complete the online questionnaire on their own time. A reminder email was sent 2 weeks after initial distribution. The survey was online for 1 month.

A pilot version of the questionnaire was tested by six teachers and six postgraduate students of the master's degree in Integrated Paediatric Dentistry, University of Murcia, to ensure the questions had been correctly prepared, were easily understandable and did not entail a prolonged response time.

\section{Survey instrument (Supplementary file 1)}

The questionnaire was divided into two main sections. The first section covered demographics (age group, years of practice, occupational sector, qualification), educational background (main area of work), perception (changes in the incidence of MIH lesions in recent years), clinical appearance (severity of $\mathrm{MIH}$ lesions, similar lesions in the second temporary molar), prevalence (how often do they see MIH lesions, how many patients present them), participants' attitudes, knowledge (aetiology) and practice in MIH management and, finally, restorative options in $\mathrm{MIH}$ management (types of restoration material and factors that influence the choice).

In the second part of the questionnaire, two clinical situations with illustrative photographs and a written case description were suggested to dentists. In clinical case 1 (Fig. 1), dentists were asked which treatment they would prefer for a semi-erupted first permanent molar with moderate $\mathrm{MIH}$, post-eruptive fracture and sensitivity in the tooth in a seven-year-old patient. The options were: fluoride varnish, restoration with GIC, restoration with composite, extraction and "I am not sure of the best option". In clinical case 2 (Fig. 2), dentists were asked about the best treatment for a delimited brown 


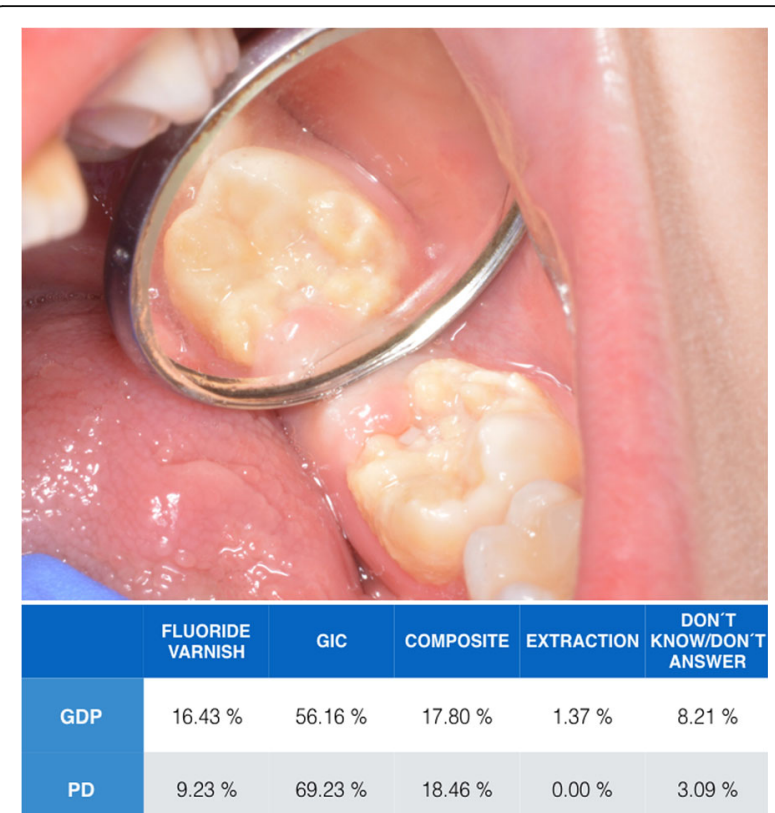

Fig. 1 In clinical case 1, dentists were asked which treatment they would prefer for a semi-erupted primary molar with moderate $\mathrm{MIH}$, post-eruptive fracture and sensitivity in the tooth in a seven-year-old patient. The options were: (1) Fluoride varnish, (2) Restoration with glass ionomer cement (GIC) (3) Restoration with resin composite (4) Extraction of the tooth (5) I am not sure of the best option

opacity without post-eruptive enamel fracture. The options were: eliminate all tissue affected by MIH and restore, eliminate only the most affected tissue and restore, and do not eliminate any dental tissue and restore. The options for restorative material were resin composite, GIC and temporary restoration.

The questions in the first section of the questionnaire, where it says "tick one option", and the first clinical case have only one answer. The second clinical case, and the questions where it says "choose the corresponding answers", are multiple choice, so the number of responses could be greater than the number of respondents.

\section{Data analysis}

Study data were processed and analysed using the R statistical package. A simple frequency distribution was made. Independent variables (sociodemographic variables: Table 1) and dependent variables (remaining survey questions: Tables 2,3 and 4) were tabulated for GDPs and PDs. To identify differences in dependent variables between GDPs and PDs, Pearson's chi-square test was applied in contrasts where the required assumptions were met, and Fisher's exact test in which they were not ( $p$-value $<0.05$ and significance level 0.05 ). Cramer's test was used to determine whether the relationship was strong or weak.

\section{Results}

Of the 1147 dentists invited to participate, 216 responded. Two surveys were eliminated because they were not completed correctly, resulting in a response rate of $18.66 \%(n=214): 69.16 \%$ were GDPs or other specialties $(n=148)$, and $30.84 \%$ were PDs $(n=66)$.

Of the participants, $44.86 \%$ were aged $31-40$ years, $39.72 \%$ had $>15$ years of practical experience, $84.58 \%$ worked in the private sector, and $74.30 \%$ were licensed in Dentistry (Table 1).

The perception of GDPs and PDs about MIH is shown in Table 2: $59.46 \%$ of GDPs make diagnoses of $\mathrm{MIH}$ monthly, while $72.73 \%$ of PDs diagnose MIH weekly.

In terms of prevalence, $59.45 \%$ of GDPs found that < $10 \%$ of their patients had MIH, while $50.00 \%$ of PDs said that $10-25 \%$ of their patients had MIH. In addition, 95.45\% of PDs had detected an increase in the incidence of MIH in recent years $(p<0.001)$.

Yellow-brown demarcated opacities were the most common clinical forms detected, both by PDs (65.16\%) and GDPs (58.11\%) and were most often diagnosed in the permanent teething.

The knowledge of respondents regarding the aetiology of MIH is shown in Table 3. Many factors were mentioned, but chronic medical conditions affecting children $(p=0.029)$ and environmental pollutants $(p=0.008)$ were the only factors that showed significant differences between the two groups.

As for the difficulty of managing MIH, the most frequent response was that it is considered a challenge and that GPDs $(76.19 \%)$ had not received any information on this $(p<0.001)$. PDs stated that the information they obtain on MIH basically comes from face-to-face continuing education (44.26\%), while the Internet was the source of choice for GDPs $(36.15 \%)(p=0.005)$, with widespread demand for information on the aetiology, diagnosis and treatment of MIH.

The results on restorative treatments in $\mathrm{MIH}$ are shown in Table 4. Significant differences between GDPs and PDs in the choice of material characteristics were identified, such as durability $(p=0.009)$ and remineralization potential $(p=0.018)$. As for the material of choice in cases of post-eruptive fractures, RMGIC was the most widely used by both groups. However, there were significant differences in the use of glass ionomer cement (GIC) $(p=0.048)$ between GDPs (12.21\%) and PDs (18.40\%). No significant differences were found in the materials used to restore opacity, with RMGIC again being the first choice in both groups. However, in the case of the treatment of lesions in the incisors, composite was the material of choice in both groups, with significant differences $(p=0.032)$ in the use of RMGIC between GDPs and PDs. 


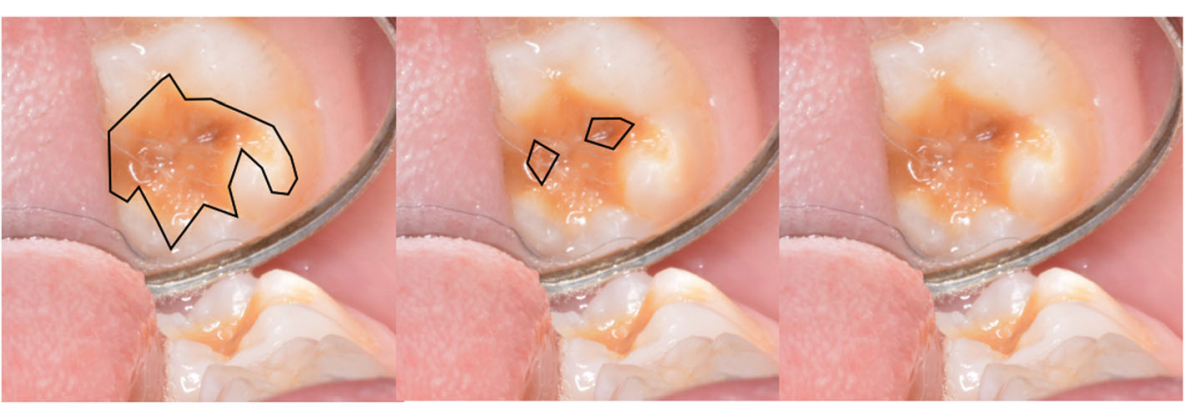

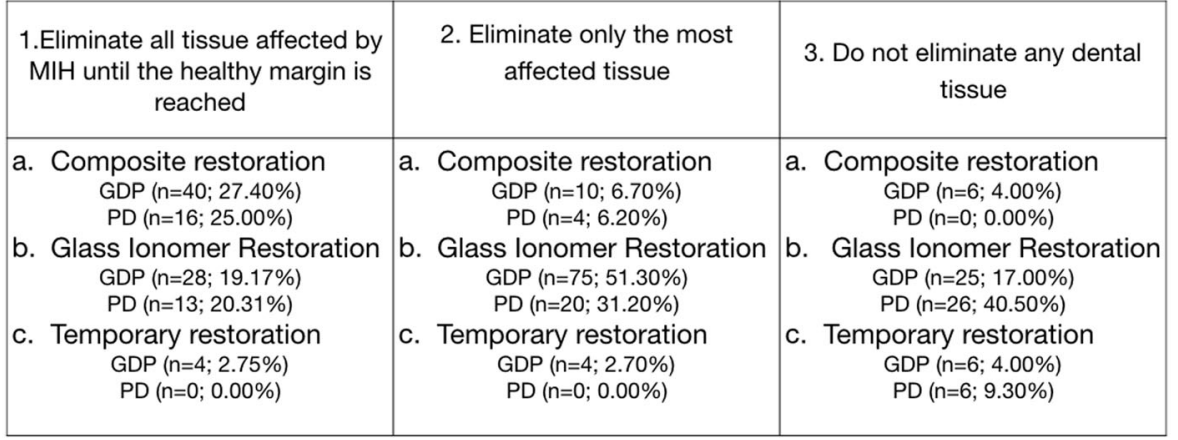

Fig. 2 In clinical case 2, dentists were asked about the best treatment for a delimited brown opacity without post-eruptive enamel fracture. The options were: (1A) Eliminate all tissue affected by MIH and restore with resin composite; (1B) Eliminate all affected tissue and restore with glass ionomer cement (GIC); (1C) Eliminate all affected tissue and make a temporary restoration; (2A) Eliminate only the most affected tissue and restore with composite; (2B) Eliminate only the most affected tissue and restore with glass ionomer; (2C) Eliminate only the most affected tissue and make a temporary restoration; (3A) Do not eliminate any dental tissue and restore with composite;(3B) Do not eliminate any dental tissue and restore with glass ionomer (GIC); (3C) Do not eliminate any dental tissue and make a temporary restoration

Table 1 Demographic characteristics of study participants

\begin{tabular}{|c|c|c|c|}
\hline Characteristics & $\begin{array}{l}\text { Total } \\
\text { n (\%) }\end{array}$ & $\begin{array}{l}\text { GDPs } \\
\text { n (\%) }\end{array}$ & $\begin{array}{l}\text { PDs } \\
\text { n (\%) }\end{array}$ \\
\hline Age group & $214(100)$ & $148(100)$ & $66(100)$ \\
\hline$<30$ & $56(26.17)$ & $37(25.00)$ & 19 (28.79) \\
\hline $31-40$ & $96(44.86)$ & $67(45.27)$ & $29(43.94)$ \\
\hline $41-50$ & $33(15.42)$ & $23(15.54)$ & $10(15.15)$ \\
\hline$>50$ & $29(13.55)$ & $21(14.19)$ & $8(12.12)$ \\
\hline Years of practice & $214(100)$ & $148(100)$ & $66(100)$ \\
\hline$<5$ & $47(21.96)$ & $35(23.65)$ & $12(18.18)$ \\
\hline $6-10$ & $37(17.29)$ & $24(16.22)$ & $13(19.70)$ \\
\hline $11-15$ & $45(21.03)$ & $33(22.30)$ & $12(18.18)$ \\
\hline$>15$ & 85 (39.72) & $56(37.84)$ & $29(43.94)$ \\
\hline Work Sector & $214(100)$ & $148(100)$ & $66(100)$ \\
\hline Public sector & $7(3.27)$ & $3(2.03)$ & $4(6.05)$ \\
\hline Private Sector & $181(84.58)$ & $130(87.83)$ & $51(77.26)$ \\
\hline Combined & $26(12.15)$ & $15(10.13)$ & $11(16.67)$ \\
\hline \multicolumn{4}{|l|}{ Qualification (degree level) } \\
\hline Stomatologist & $23(10.75)$ & $18(12.162)$ & $5(7.57)$ \\
\hline Dentistry Licenciated (up to 2010) & $159(74.30)$ & $104(70.27)$ & $55(83.33)$ \\
\hline Dentistry Graduated (later than 2010) & $32(14.95)$ & $26(17.57)$ & $6(9.08)$ \\
\hline
\end{tabular}


Table $2 \mathrm{MlH}$ perception, clinical appearance and prevalence according to study participants

\begin{tabular}{|c|c|c|c|c|}
\hline Question & $\begin{array}{l}\text { Total } \\
\text { n (\%) }\end{array}$ & $\begin{array}{l}\text { GDPs } \\
\text { n (\%) }\end{array}$ & $\begin{array}{l}\text { PDs } \\
\text { n (\%) }\end{array}$ & $P$-Value \\
\hline How often do you notice hypomineralized teeth in your practice? & $214(100)$ & $148(100)$ & $66(100)$ & $<0.001$ \\
\hline Weekly & $88(41.12)$ & $40(27.02)$ & $48(72.73)$ & \\
\hline Monthly & $104(48.59)$ & $88(59.46)$ & $16(24.24)$ & \\
\hline Annually & $22(10.28)$ & $20(13.50)$ & $2(3.03)$ & \\
\hline Approximately what percentage of your patients present this defect? & $214(100)$ & $148(100)$ & $66(100)$ & $<0.001$ \\
\hline$<10 \%$ & $104(48.59)$ & $88(59.45)$ & $16(24.24)$ & \\
\hline $10-25 \%$ & $87(40.65)$ & $54(36.48)$ & $33(50.00)$ & \\
\hline$>25 \%$ & $23(10.74)$ & $6(4.05)$ & $17(25.76)$ & \\
\hline Do you perceive that the incidence of MIH has increased in recent years? & $214(100)$ & $148(100)$ & $66(100)$ & $<0.001$ \\
\hline No & $41(19.15)$ & $38(25.67)$ & $3(4.54)$ & \\
\hline Yes & $173(80.84)$ & $110(74.32)$ & $63(95.45)$ & \\
\hline What do you most frequently notice in your practice? & $214(100)$ & $148(100)$ & $66(100)$ & 0.375 \\
\hline White demarcated opacities & $78(36.45)$ & 58 (39.19) & $20(30.30)$ & \\
\hline Yellow/brown demarcated opacities & $129(60.28)$ & $86(58.11)$ & $43(65.16)$ & \\
\hline Post-eruptive enamel breakdown & $7(3.27)$ & $4(2.7)$ & $3(4.54)$ & \\
\hline How frequently do you notice this defect in the second primary molar? & $210(100)$ & $144(100)$ & $66(100)$ & 0.516 \\
\hline More often & $9(4.28)$ & $5(3.47)$ & $4(6.06)$ & \\
\hline Equally as often & $15(17.14)$ & $12(8.33)$ & $3(4.54)$ & \\
\hline Less often & $186(88.57)$ & $127(88.19)$ & 59 (89.39) & \\
\hline
\end{tabular}

GDPs General dental practitioners, PDs Pediatric dentists

In the second part of the questionnaire, in the first clinical case (Fig. 1), the material of choice for most respondents was GIC in both groups (GDPs: $56.1 \%$ vs. PD: 69.1\%). In the second clinical case (Fig. 2), 51\% of GDPs supported removal of only the most affected tissue and restoration with GIC. However, a more conservative attitude was observed among PDs (40.5\%), who stated they would not remove any enamel and would restore with GIC.

\section{Discussion}

Despite the high prevalence and increased incidence of MIH in Spanish paediatric patients, this is the first study to provide information on the perception and knowledge of the aetiology and diagnosis of MIH and patient management strategies of Spanish GDPs and PDs.

We used an online survey to avoid the low response rate obtained in postal surveys [23]. The response rate was $18.6 \%$, despite a reminder sent at 2 weeks. Although the response was low, it was similar to that recorded in similar studies in other countries $[8,13,16,19,21]$ and in various dental studies $[24,25]$. The response rate in surveys of health care workers is falling, despite the use of new technologies. However, surveys continue to be an important source of information on the knowledge, attitudes, opinions, and practices associated with new or controversial topics [26]. The response rate has often been regarded as a measure of the quality of the work, but there is no scientifically accepted minimum response rate. Non-response bias, meaning respondents do not represent the target population, is more of a problem in surveys in the general population than in those in specific groups such as physicians [27] or, in our case, dentists.

In Spain, dentistry is mostly private, which is reflected by the responders ( $84.58 \%$ private), unlike countries such as Norway [14] or Australia and Chile [19] where most dentists are public. We found that $69.16 \%$ of participants were GDPs and 30.84\% PDs. PD training in Spain is not specialized, as in most European Union countries, but is a postgraduate master. In both groups of dentists, the majority $(74.30 \%)$ of practitioners were licensed in Dentistry, with a mean age of $31-40$ years $(44.86 \%)$ and with $>15$ years of professional experience $(39.72 \%)$. The professional profiles found in other studies vary in age and years of experience, with the study conducted in Hong Kong having the oldest professionals and the greatest professional experience [8].

We found that PDs had twice the perception of patients with MIH lesions compared with GDPs, a situation reflected in countries such as Iraq [15], Malaysia [22], Australia-New Zealand [18], Saudi Arabia [17], China [8] and the UK [20], where the prevalence of MIH is similar to Spain. Both in Spain and in other countries 
Table $3 \mathrm{MIH}$ management considerations, source of information, and clinical training demand according to study participants

\begin{tabular}{|c|c|c|c|c|}
\hline Question & $\begin{array}{l}\text { Total } \\
\text { n (\%) }\end{array}$ & $\begin{array}{l}\text { GDPs } \\
\text { n (\%) }\end{array}$ & $\begin{array}{l}\text { PDs } \\
\text { n (\%) }\end{array}$ & $P$-Value \\
\hline Which factors do you think are involved in the etiology of MIH? ${ }^{a}$ & $827(100)$ & $535(100)$ & $292(100)$ & \\
\hline Genetic factors & $107(12.93)$ & $77(14.39)$ & $30(10.27)$ & 0.459 \\
\hline Acute medical condition that affects the mother during pregnancy & $110(13.30)$ & $74(13.83)$ & $36(12.32)$ & 0.641 \\
\hline Acute medical condition that affects the child involved & $93(11.24)$ & $61(11.40)$ & $32(10.95)$ & 0.401 \\
\hline Antibiotics/medications taken by the mother during pregnancy & $90(10.88)$ & $56(10.46)$ & $34(11.64)$ & 0.085 \\
\hline Antibiotics/medications taken by the child involved & $115(13.90)$ & $73(13.64)$ & $42(14.72)$ & 0.073 \\
\hline Chronic medical condition that affects the mother during pregnancy & 75 (9.06) & $47(8.78)$ & $28(9.58)$ & 0.175 \\
\hline Chronic medical condition that affects the child involved & $76(9.18)$ & $45(8.41)$ & $31(10.61)$ & 0.029 \\
\hline Environmental contaminants & $96(11.60)$ & $57(10.65)$ & $39(13.35)$ & 0.008 \\
\hline Fluoride exposure & $65(7.85)$ & $45(8.41)$ & $20(6.85)$ & 1 \\
\hline Do you think the management of MIH is a challenge? & $213(100)$ & $148(100)$ & $65(100)$ & 0.837 \\
\hline Yes, very difficult & $72(33.80)$ & $52(35.13)$ & $20(30.76)$ & \\
\hline Yes, somewhat difficult & $127(59.62)$ & $86(58.10)$ & $41(63.07)$ & \\
\hline No & $14(6.57)$ & $10(6.76)$ & $4(6.15)$ & \\
\hline Which are the biggest difficulties? ${ }^{a}$ & $649(100)$ & $439(100)$ & $210(100)$ & \\
\hline Diagnosis & $42(6.47)$ & $29(6.60)$ & $13(6.19)$ & 1 \\
\hline Esthetics & $66(10.17)$ & $42(9.57)$ & $24(11.42)$ & 0.385 \\
\hline Long-term success of restoration & $173(26.65)$ & $120(27.33)$ & $53(25.23)$ & 0.657 \\
\hline Correct determination of restoration margins & $124(19.10)$ & $89(20.27)$ & $35(16.66)$ & 0.266 \\
\hline Achieving correct local anesthetic & $72(11.09)$ & $42(9.57)$ & $30(14.28)$ & 0.031 \\
\hline Providing correct restoration & $144(22.18)$ & $100(22.77)$ & $44(20.95)$ & 0.765 \\
\hline Other & $28(4.31)$ & $17(3.87)$ & $11(5.29)$ & 0.464 \\
\hline Do you receive any information on $\mathrm{MIH}$ ? & $213(100)$ & $147(100)$ & $66(100)$ & $<0.001$ \\
\hline Yes & $74(34.74)$ & $35(23.80)$ & $39(59.09)$ & \\
\hline No & $139(65.25)$ & $112(76.19)$ & $27(40.90)$ & \\
\hline Where do you obtain the information & $194(100)$ & $130(100)$ & $61(100)$ & 0.005 \\
\hline Journals & $34(17.52)$ & $24(18.46)$ & $10(16.39)$ & \\
\hline Continuing education & $54(27.83)$ & $27(20.77)$ & $27(44.26)$ & \\
\hline Brochures & $4(2.06)$ & $4(13.07)$ & $0(0)$ & \\
\hline Internet & $58(29.89)$ & $47(36.15)$ & $11(18.03)$ & \\
\hline Books & $10(5.15)$ & $5(3.84)$ & $5(8.19)$ & \\
\hline Others & $31(15.98)$ & $23(17.69)$ & $8(13.11)$ & \\
\hline Where do you think more information is necessary? & $212(100)$ & $146(100)$ & $66(100)$ & 0.023 \\
\hline Etiology & $19(8.96)$ & $8(5.47)$ & $11(16.66)$ & \\
\hline Diagnosis & $1(0.47)$ & $0(0.00)$ & $1(1.51)$ & \\
\hline Treatment & 69 (32.54) & $51(34.93)$ & $18(27.27)$ & \\
\hline All & $123(58.01)$ & 87 (59.59) & $36(54.54)$ & \\
\hline
\end{tabular}

GDPs General dental practitioners, PDs Pediatric dentists.

a These questions are multiple choice, so the number of responses could be greater than the number of respondents $(n=214)$

$[15,17,18]$, the general perception of dentists is that there is an increase in the incidence of $\mathrm{MIH}$, although in our case the perception is significantly higher in PDs than in GDPs. Thus, $59.45 \%$ of GDPs responded that the prevalence of MIH patients is $<10 \%$. GDPs from countries such as the USA [21] India [16] and China [8] estimated the prevalence at $<5 \%$. These results are closely related to the training of dentists and their diagnostic 
Table 4 Restorative management options for molar incisor hypomineralization (MIH)

\begin{tabular}{|c|c|c|c|c|}
\hline Question & $\begin{array}{l}\text { Total } \\
\text { n (\%) }\end{array}$ & $\begin{array}{l}\text { GDPs } \\
\text { n (\%) }\end{array}$ & $\begin{array}{l}\text { PDs } \\
\text { n (\%) }\end{array}$ & $P$-Value \\
\hline Factors in the choice of material $^{a}$ & $577(100)$ & $392(100)$ & $185(100)$ & \\
\hline Adhesion & $137(23.74)$ & $96(24.48)$ & $41(22.16)$ & 0.817 \\
\hline Durability & $124(21.49)$ & $95(24.23)$ & $29(15.67)$ & 0.009 \\
\hline Experience & $30(5.20)$ & $18(4.59)$ & $12(6.48)$ & 0.338 \\
\hline Remineralization potential & $146(25.30)$ & $93(23.72)$ & $53(13.52)$ & 0.018 \\
\hline Patient/parent preferences & $8(1.38)$ & $6(1.53)$ & $2(0.51)$ & 1 \\
\hline Sensitivity & $84(14.55)$ & $53(13.52)$ & $31(7.91)$ & 0.175 \\
\hline Research findings & $48(8.32)$ & $31(7.91)$ & $17(4.33)$ & 0.547 \\
\hline Material of choice for post-eruptive fractures ${ }^{a}$ & $387(100)$ & $262(100)$ & $125(100)$ & \\
\hline Compomer & $13(3.35)$ & $10(3.81)$ & $3(2.4)$ & 0.758 \\
\hline Composite resin & $88(22.74)$ & $59(22.51)$ & $29(23.2)$ & 0.674 \\
\hline Flowable composite resin & $18(4.65)$ & $15(5.72)$ & $3(2.40)$ & 0.285 \\
\hline Stainless steel crown & $38(9.82)$ & $26(9.92)$ & $12(9.60)$ & 1 \\
\hline Silver diamine fluoride & $6(1.55)$ & $4(1.53)$ & $2(1.60)$ & 1 \\
\hline Cast restoration & $23(5.94)$ & $16(6.11)$ & $7(5.60)$ & 1 \\
\hline $\mathrm{GIC}$ & $55(14.21)$ & $32(12.21)$ & $23(18.40)$ & 0.048 \\
\hline RMGIC & $139(35.91)$ & $95(36.25)$ & $44(35.20)$ & 0.831 \\
\hline Others & $7(1.81)$ & $5(1.90)$ & $2(1.60)$ & 1 \\
\hline Material of choice for opacities ${ }^{a}$ & $316(100)$ & $216(100)$ & $100(100)$ & \\
\hline Amalgam & $4(1.26)$ & $4(1.85)$ & $0(0.00)$ & 0.315 \\
\hline Compomer & $18(5.69)$ & $15(6.94)$ & $3(3.00)$ & 0.284 \\
\hline Composite resin & $87(27.53)$ & $61(28.24)$ & $26(26.00)$ & 0.966 \\
\hline Flowable composite resin & $25(7.91)$ & $17(7.87)$ & $8(8.00)$ & 1 \\
\hline Stainless steel crowns & $6(1.89)$ & $5(2.31)$ & $1(1.00)$ & 0.669 \\
\hline Silver diamine fluoride & $18(5.69)$ & $11(5.09)$ & $7(7.00)$ & 0.597 \\
\hline $\mathrm{GIC}$ & $42(13.29)$ & $25(11.57)$ & $17(17.00)$ & 0.173 \\
\hline RMGIC & 109 (34.49) & $72(33.33)$ & $37(37.00)$ & 0.348 \\
\hline Others & $7(2.21)$ & $6(2.77)$ & $1(1.00)$ & 0.678 \\
\hline Material of choice for hypomineralized incisors ${ }^{a}$ & $318(100)$ & $209(100)$ & $109(100)$ & \\
\hline Compomer & $12(3.77)$ & $8(3.82)$ & $4(3.66)$ & 1 \\
\hline Composite resin & $122(38.36)$ & $86(41.14)$ & $36(33.02)$ & 0.794 \\
\hline Flowable composite resin & $40(12.57)$ & $27(12.91)$ & $13(11.95)$ & 0.924 \\
\hline Stainless steel crowns & $1(0.31)$ & $1(0.47)$ & $0(0.00)$ & 1 \\
\hline Silver diamine fluoride & $3(0.94)$ & $2(0.95)$ & $1(0.91)$ & 1 \\
\hline Resin infiltration & $52(16.35)$ & $35(16.74)$ & $17(15.59)$ & 0.841 \\
\hline $\mathrm{GIC}$ & $15(4.71)$ & $7(3.34)$ & $8(7.33)$ & 0.077 \\
\hline RMGIC & $62(19.49)$ & $36(17.22)$ & $26(23.85)$ & 0.032 \\
\hline Other & $11(3.45)$ & $7(3.34)$ & $4(3.66)$ & 0.739 \\
\hline
\end{tabular}

GDPs General dental practitioners, PDs Pediatric dentists, GIC Glass ionomer cement, RMGIC Resin-modified glass ionomer cement

a These questions are multiple choice, so the number of responses could be greater than the number of respondents ( $n=214$ )

ability: $59.09 \%$ of PDs claimed to have training in $\mathrm{MIH}$ compared with $23.80 \%$ of GDPs. In addition, training was received in continuous education courses, compared with the online self-training described by GDPs. In other countries, the training of PDs in MIH shows similar results, although GDPs had less training in MIH (7.0- 
8.8\%) $[16,28]$. Despite these results, both PDs and GDPs in Spain require ongoing training courses on $\mathrm{MIH}$ [8, $15,16,19]$.

The most recognized $\mathrm{MIH}$ lesion in both study groups was yellow/brown lesions, as it was in other countries [13, 15-18]. This may be because white-cream lesions may be mistaken for other lesions, such as fluorosis or white spot cavities [20, 29]. The percentage of posteruptive enamel fractures was low, possibly because they may be confused with extensive cavity lesions, with atypical restorations typical of this pathology, since the enamel breaks quickly after rupture $[15,30]$, or with enamel hypoplasia, although in this case the borders of the lesion are not as irregular as in MIH [20].

In 2012, hypomineralization of the primary teeth was described, mainly in the second primary molars (HSPM). This is known to be associated with an increased risk of hypomineralization in the permanent molars, although the absence of HSPM does not exclude future MIH [2]. Most of our respondents report detecting HSPM less frequently, with no differences between the two groups, as is the case in studies in the USA [21], Kuwait [13], Saudi Arabia [17] and Australia-Chile [19], even though PDs have greater access to paediatric populations, where the diagnosis should be more common.

In general, and as in other studies [8, 15-18, 21], dentists' responses reflect the hypothesis that the aetiology may be multifactorial, with a diversity of responses. Most studies, when describing etiological factors, attribute MIH primarily to chronic and acute medical conditioners affecting the mother and child [8, 15, 16, 19]. In our study, $42.80 \%$ of dentists attributed the aetiology to these factors, lower than the $80-100 \%$ found in other studies $[8,18]$. The second cause, in our study, was the consumption of antibiotics by the child or mother during pregnancy $(24.78 \%)$, figures similar to the Iran study [15] but below the studies in Hong Kong [8] and Australia-New Zealand [18]. Environmental pollutants were considered causal agents by $11.6 \%$, with a different perception between GDPs and DPs.

A significant percentage of both GDPs and PDs responded that they found the management of $\mathrm{MIH}$ "somewhat difficult". This is because these patients have increased anxiety [31] and tooth hypersensitivity, even after local anaesthesia. In fact, anaesthesia is one of the procedures that mark significant differences between dentists, with GDPs finding it more difficult to achieve good anaesthesia than PDs.

Achieving correct restoration and long-term success is what worries dentists the most (48.84\%). It is known that etching with orthophosphoric acid creates faulty etched patterns [32], that resin penetration is defective and the adhesion force of the composite resins to the enamel affected by $\mathrm{MIH}$ is low [33], and that there is a high failure rate of this type of material in molars with $\mathrm{MIH}$ [34]; in fact, the second most relevant factor in the choice of material by our dentists is material adhesion (23.74\%).

There are many reported treatment options for the restoration of teeth with $\mathrm{MIH}$ lesions: fluoride and/or CPP-ACP remineralization systems, silver diamine fluoride, pit and fissure sealants, resin infiltrations, conventional and modified glass ionomers with resin, resin composite, amalgam, preformed crowns, and even extractions, always depending on the severity of the lesion [28].

The potential for remineralization of material in restoration is the most relevant factor in the choice of materials (25.3\%), significantly worrying GDPs more than PDs. In fact, the most commonly used material to restore post-eruptive fractures is RMGIC, followed by composite and both are used equally by GDPs and PDs. GIC is the third material of choice and is used proportionally more by PDs than GDPs. This may be because they treat younger children and use it as filling material in atraumatic restorative treatments or for interim restorations. Durability, which is one of the most relevant factors in material choice, is therefore significantly less decisive for PDs than for GDPs.

There are studies that show GIC (81\%) was used more than RMGIC (44.3\%), which is justified by the greater fluoride release [18]. However, a recent systematic review showed that the failure rate of restorative materials in the treatment of MIH is higher with the use of amalgams and glass ionomers, and the highest success rate is achieved with indirect restorations, preformed stainless steel crowns (SSC) and composite restorations [28]. In other studies, composite was the material of choice $[8,13,17$, 18], and was recommended by Lygidakis et al. [30] in moderate lesions. In our study, the number of SSCs was very low compared with other studies $[8,16,18]$ in which it was the treatment of choice in fractures for most PDs. Some authors recommend them for moderate and severe $\mathrm{MIH}$ lesions instead of GIC and RMGIC [30].

With respect to enamel opacity, the materials chosen were the same in both groups; first RMGIC followed by composite. However, in incisor lesions, composite was the material of choice, due to aesthetic concerns, followed by RMGIC and resin infiltrations. PDs use significantly more RMGIC to restore incisor enamel lesions.

The adhesion, durability and potential for remineralization were also decisive in the choice of material by most dentists from other countries [8, 16, 18]. We left open the possibility of "other materials" where dentists could introduce other options used in combination with those defined in the survey. However, there were only $1.81-$ $3.45 \%$ of responses. In contrast, in the Hong Kong study, 96.3\% of PDs used fluoride varnishes and 64\% pit fissure sealants [8]. 
In clinical case 1 (Fig. 1), where a post-eruptive enamel fracture was presented in a semi-erupted tooth, the material selected by both groups for treatment was GIC, followed by composite, similar to the results of the Norwegian study [14]. Difficult moisture control in a semierupted molar and fluoride release were the main reasons for choosing GIC. The limited mechanical properties of GIC mean it should be considered an interim therapeutic restoration and must be replaced by another, definitive material (composite or preformed crowns) when eruption is complete [31].

In clinical case 2, the preferred option for GDPs was to remove the tissue seemingly most affected and restore with glass ionomer, compared with PDs whose option was not to remove any dental tissue and use glass ionomer to restore. This shows a trend towards less invasive treatment by PDs, as described by other reports [14].

The study had some limitations. First, the response rate was low, although this is characteristic of online surveys. Secondly, it was aimed at dentists from one Spanish region. Therefore, extrapolation of the results to the rest of Spain, should be made with caution, as sociodemographic characteristics may vary. However, the survey may serve as a starting point for the introduction of Spanish guidelines or protocols on the correct care of children with $\mathrm{MIH}$.

\section{Conclusion}

Spanish dentists perceive that the incidence of MIH has increased in recent years. They believe it is difficult or very difficult to manage $\mathrm{MIH}$, since the long-term success of restorations of MIH lesions is compromised because resin adhesion is not good. They use RMGICs more frequently, taking advantage of their remineralizing potential, except in the incisors, where they use composites. Both GDPs and PDs think they need more training on the aetiology, diagnosis, and treatment of MIH. The introduction of national guidelines that serve as a reference manual for all continuing education courses would improve the management of $\mathrm{MIH}$.

\section{Supplementary information}

Supplementary information accompanies this paper at https://doi.org/10. 1186/s12903-020-01249-6.

\section{Additional file 1.}

\section{Abbreviations \\ MIH: Molar incisor hypomineralization; GDPs: General dental practitioners; PDs: Paediatric dentists; RMGIC: Resin-modified glass ionomer; HSPM: Hypomineralized second primary molar; GIC: Glass ionomer cement; UK: United Kingdom; SSC: Stainless steel crowns}

\section{Acknowledgements}

The authors thank the College of Dentists of Murcia for facilitating dissemination of the survey among its members.
Authors' contributions

CSM, AJOR and YMB investigated the idea of the study, developed the protocol and carried out the fieldwork. FJRL conducted data analysis. APS and APP prepared figure and tables. All authors wrote and reviewed the manuscript. The author(s) read and approved the final manuscript.

\section{Funding}

No funding was received from any organization or individuals.

\section{Availability of data and materials}

The datasets used for the current study are available from the corresponding author on reasonable request.

\section{Ethics approval and consent to participate}

Ethical approval was obtained from the Bioethics Committee of Murcia University (Reference Number: 2255/2019). The questionnaire was anonymous and informed consent was considered as agreeing to participate in the survey.

\section{Consent for publication \\ Not applicable.}

\section{Competing interests}

The authors declare that they have no competing interests.

\section{Author details}

'Department of Integrated Paediatric Dentistry, Faculty of Medicine-Dentistry, University of Murcia, Murcia, Spain. ${ }^{2}$ Unit of Preventive and Community Dentistry, Department of Dermatology, Stomatology, Radiology and Physical Medicine, Faculty of Medicine-Dentistry, University of Murcia, Hospital Morales Meseguer, 2a planta, C/ Marqués de los Vélez, s/n., 30007 Murcia, Spain. ${ }^{3}$ Department of Stomatology, Faculty of Medicine-Nursing, University of the Basque Country, Leioa, Spain. ${ }^{4}$ Scientific and Technical Research Area, Statistical Service, University of Murcia, Murcia, Spain.

Received: 15 May 2020 Accepted: 8 September 2020

Published online: 18 September 2020

\section{References}

1. Weerheijm KL, Duggal M, Mejàre I, Papagiannoulis L, Koch G, Martens LC, et al. Judgement criteria for molar incisor hypomineralisation $(\mathrm{MIH})$ in epidemiologic studies: a summary of the European meeting on $\mathrm{MIH}$ held in Athens, 2003. Eur J Paediatr Dent. 2003:4:110-3.

2. Elfrink MEC, ten Cate JM, Jaddoe WW, Hofman A, Moll HA, Veerkamp JSJ. Deciduous molar hypomineralization and molar incisor hypomineralization. J Dent Res. 2012;91:551-5.

3. Weerheijm KL, Jälevik B, Alaluusua S. Molar-incisor hypomineralisation. Caries Res. 2001;35:390-1.

4. Serna C, Vicente A, Finke C, Ortiz AJ. Drugs related to the etiology of molar incisor hypomineralization: a systematic review. J Am Dent Assoc. 2016;147: 120-30.

5. Meligy OAESE, Alaki SM, Allazzam SM. Molar incisor hypomineralization in children: a review of literature. J Oral Hyg Health. 2014;2:1-5.

6. Garg N, Jain AK, Saha S, Singh J. Essentiality of early diagnosis of molar incisor hypomineralization in children and review of its clinical presentation, etiology and management. Int J Clin Pediatr Dent. 2012;5:190-6.

7. Elfrink MEC, Ghanim A, Manton DJ, Weerheijm KL. Standardised studies on molar incisor hypomineralisation $(\mathrm{MIH})$ and hypomineralised second primary molars (HSPM): a need. Eur Arch Paediatr Dent. 2015;16:247-55.

8. Gamboa GCS, Lee GHM, Ekambaram M, Yiu CKY. Knowledge, perceptions, and clinical experiences on molar incisor hypomineralization among dental care providers in Hong Kong. BMC Oral Health. 2018;18:217.

9. Hernández M, Boj J-R, Espasa E, Peretz B. First permanent molars and permanent incisors teeth by tooth prevalence of molar-incisorhypomineralisation in a group of Spanish schoolchildren. Acta Stomatol Croat. 2018:52:4-11.

10. Negre-Barber A, Montiel-Company JM, Boronat-Catalá M, Catalá-Pizarro M, Almerich-Silla JM. Hypomineralized second primary molars as predictor of molar incisor hypomineralization. Sci Rep. 2016;6:31929.

11. Martínez Gómez TP, Guinot Jimeno F, Bellet Dalmau LJ, Giner Tarrida L. Prevalence of molar-incisor hypomineralisation observed using 
transillumination in a group of children from Barcelona (Spain). Int $J$ Paediatr Dent. 2012;22:100-9.

12. Garcia-Margarit M, Catalá-Pizarro M, Montiel-Company JM, Almerich-Silla JM. Epidemiologic study of molar-incisor hypomineralization in 8-year-old Spanish children. Int J Paediatr Dent. 2014;24:14-22.

13. Alanzi A, Faridoun A, Kavvadia K, Ghanim A. Dentists' perception, knowledge, and clinical management of molar-incisor-hypomineralisation in Kuwait: a cross-sectional study. BMC Oral Health. 2018;18:34.

14. Kopperud SE, Pedersen CG, Espelid I. Treatment decisions on molar-incisor hypomineralization $(\mathrm{MIH})$ by Norwegian dentists - a questionnaire study. BMC Oral Health. 2016;17:3

15. Ghanim A, Morgan M, Mariño R, Manton D, Bailey D. Perception of molarincisor hypomineralisation $(\mathrm{MIH})$ by Iraqi dental academics. Int J Paediatr Dent. 2011;21:261-70.

16. Upadhyay S, Kumar G, Dhillon JK, Gill NC. Perception of Indian dental surgeons regarding molar incisor hypomineralization. Int I Clin Pediatr Dent. 2018:11:116-21.

17. Silva MJ, Alhowaish L, Ghanim A, Manton DJ. Knowledge and attitudes regarding molar incisor hypomineralisation amongst Saudi Arabian dental practitioners and dental students. Eur Arch Paediatr Dent. 2016;17:215-22.

18. Crombie FA, Manton DJ, Weerheijm KL, Kilpatrick NM. Molar incisor hypomineralization: a survey of members of the Australian and New Zealand Society of Paediatric Dentistry. Aust Dent J. 2008:53:160-6.

19. Gambetta-Tessini K, Mariño R, Ghanim A, Calache H, Manton DJ. Knowledge, experience and perceptions regarding molar-incisor hypomineralisation $(\mathrm{MIH})$ amongst Australian and Chilean public oral health care practitioners. BMC Oral Health. 2016;16:75.

20. Kalkani M, Balmer RC, Homer RM, Day PF, Duggal MS. Molar incisor hypomineralisation: experience and perceived challenges among dentists specialising in paediatric dentistry and a group of general dental practitioners in the UK. Eur Arch Paediatr Dent. 2016;17:81-8.

21. Tagelsir A, Dean JA, Eckert GJ, Martinez-Mier EA. U.S. pediatric dentists' perception of molar incisor hypomineralization. Pediatr Dent. 2018;40:272-8.

22. Hussein AS, Ghanim AM, Abu-Hassan MI, Manton DJ. Knowledge, management and perceived barriers to treatment of molar-incisor hypomineralisation in general dental practitioners and dental nurses in Malaysia. Eur Arch Paediatr Dent. 2014;15:301-7.

23. Locker D, Grushka M. Response trends and nonresponse bias in a mail survey of oral and facial pain. J Public Health Dent. 1988;48:20-5.

24. Hardigan PC, Succar CT, Fleisher JM. An analysis of response rate and economic costs between mail and web-based surveys among practicing dentists: a randomized trial. J Community Health. 2012;37:383-94.

25. Schwendicke F, Stangvaltaite L, Holmgren C, Maltz M, Finet M, Elhennawy K, et al. Dentists' attitudes and behaviour regarding deep carious lesion management: a multi-national survey. Clin Oral Investig. 2017;21:191-8.

26. Klabunde CN, Willis GB, McLeod CC, Dillman DA, Johnson TP, Greene SM, et al. Improving the quality of surveys of physicians and medical groups: a research agenda. Eval Health Prof. 2012;35:477-506.

27. Berman DM, Tan LLJ, Cheng TL. Surveys and response rates. Pediatr Rev. 2015;36:364-6.

28. Elhennawy K, Schwendicke F. Managing molar-incisor hypomineralization: a systematic review. J Dent. 2016;55:16-24.

29. Ghanim A, Manton D, Mariño R, Morgan M, Bailey D. Prevalence of demarcated hypomineralisation defects in second primary molars in Iraqi children. Int J Paediatr Dent. 2013:23:48-55.

30. Lygidakis NA, Wong F, Jälevik B, Vierrou A-M, Alaluusua S, Espelid I. Best clinical practice guidance for clinicians dealing with children presenting with molar-incisor-hypomineralisation (MIH): an EAPD policy document. Eur Arch Paediatr Dent. 2010;11:75-81.

31. Jälevik B, Klingberg G. Treatment outcomes and dental anxiety in 18-yearolds with MIH, comparisons with healthy controls - a longitudinal study. Int J Paediatr Dent. 2012;22:85-91.

32. Bozal CB, Kaplan A, Ortolani A, Cortese SG, Biondi AM. Ultrastructure of the surface of dental enamel with molar incisor hypomineralization $(\mathrm{MIH})$ with and without acid etching. Acta Odontol Latinoam. 2015;28:192-8.

33. Lagarde M, Vennat E, Attal J-P, Dursun E. Strategies to optimize bonding of adhesive materials to molar-incisor hypomineralization-affected enamel: a systematic review. Int J Paediatr Dent. 2020;30:405-20.

34. Kotsanos N, Kaklamanos EG, Arapostathis K. Treatment management of first permanent molars in children with molar-incisor hypomineralisation. Eur J Paediatr Dent. 2005;6:179-84.

\section{Publisher's Note}

Springer Nature remains neutral with regard to jurisdictional claims in published maps and institutional affiliations.
Ready to submit your research? Choose BMC and benefit from:

- fast, convenient online submission

- thorough peer review by experienced researchers in your field

- rapid publication on acceptance

- support for research data, including large and complex data types

- gold Open Access which fosters wider collaboration and increased citations

- maximum visibility for your research: over $100 \mathrm{M}$ website views per year

At BMC, research is always in progress.

Learn more biomedcentral.com/submissions 